\title{
Expected Stock Returns and Variance Risk Premia
}

\author{
Tim Bollerslev \\ Duke University \\ George Tauchen \\ Duke University
}

\section{Hao Zhou \\ Federal Reserve Board}

\begin{abstract}
Motivated by the implications from a stylized self-contained general equilibrium model incorporating the effects of time-varying economic uncertainty, we show that the difference between implied and realized variation, or the variance risk premium, is able to explain a nontrivial fraction of the time-series variation in post-1990 aggregate stock market returns, with high (low) premia predicting high (low) future returns. Our empirical results depend crucially on the use of "model-free," as opposed to Black-Scholes, options implied volatilities, along with accurate realized variation measures constructed from high-frequency intraday as opposed to daily data. The magnitude of the predictability is particularly strong at the intermediate quarterly return horizon, where it dominates that afforded by other popular predictor variables, such as the $\mathrm{P} / \mathrm{E}$ ratio, the default spread, and the consumption-wealth ratio. (JEL C22, C51, C52, G12, G13, G14)
\end{abstract}

Is the return on the stock market predictable? This age-old question still ranks among the most studied and contentious in all of economics. To the extent that a consensus has emerged, it seems to be that the predictability is the strongest over long multi-year horizons. There is also evidence that the degree

\footnotetext{
Bollerslev's work was supported by a grant from the NSF to the NBER and CREATES funded by the Danish National Research Foundation. The paper combines results of an earlier paper with the same title by the first and the third authors, and a paper by the second author titled "Stochastic Volatility in General Equilibrium." Excellent research assistance was provided by Natalia Sizova. We would also like to thank an anonymous referee, John Ammer, Torben Andersen, Federico Bandi, Ravi Bansal, Oleg Bondarenko, Craig Burnside, Robert Hodrick, Pete Kyle, David Lando, Benoit Perron, Monika Piazzesi, Raman Uppal, Tuomo Vuolteenaho, Jonathan Wright, Amir Yaron, Motohiro Yogo, Alex Ziegler, and seminar participants at the Federal Reserve Board, the 2007 conference on "Return Predictability" at Copenhagen Business School, the 2007 SITE conference at Stanford, the 2007 NBER Summer Institute, the 2007 conference on "Measuring Dependence in Finance" at Cass Business School, and the 2008 Winter Meetings of the American Finance Association for helpful discussions. The views presented here are solely those of the authors and do not necessarily represent those of the Federal Reserve Board or its staff. Send correspondence to Tim Bollerslev, Department of Economics, Duke University, Durham, NC 27708; telephone: 919-660-1846; fax: 919-684-8974. E-mail: boller@econ.duke.edu.
}

(C) The Author 2009. Published by Oxford University Press on behalf of The Society for Financial Studies. All rights reserved. For Permissions, please e-mail: journals.permissions@ oxfordjournals.org. doi:10.1093/rfs/hhp008

Advance Access publication February 12, 2009 
of predictability has diminished somewhat over the past two decades. ${ }^{1}$ In lieu of this, we show that the difference between "model-free" implied and realized variances, which we term the variance risk premium, explains a nontrivial fraction of the variation in post-1990 aggregate stock market returns with high (low) values of the premium associated with subsequent high (low) returns. The magnitude of the predictability is particularly strong at the quarterly return horizon, where it dominates that afforded by other popular predictor variables, such as the P/E ratio, the default spread, and the consumption-wealth ratio (CAY).

Our empirical investigations are directly motivated by the implications from a stylized self-contained general equilibrium model. The model may be seen as an extension of the long-run risk model pioneered by Bansal and Yaron (2004), who emphasized the importance of long-run risk in consumption growth for explaining the equity premium and the dynamic dependencies in returns over long multi-year horizons. In contrast, we explicitly exclude predictability in consumption growth, focusing instead on the implications of allowing for richer and empirically more realistic volatility dynamics. Our model generates a two-factor structure for the endogenously determined equity risk premium in which the factors are directly related to the underlying volatility dynamics of consumption growth. Different volatility concepts defined within the model load differently on these fundamental risk factors. In particular, the difference between the risk-neutralized expected return variation and the realized return variation effectively isolates the factor associated with the volatility of consumption growth volatility. Consequently, the variance risk premium should serve as an especially useful predictor for the returns over horizons for which that risk factor is relatively more important. In a reasonably calibrated version of the model, this translates into population return predictability regressions that show the most explanatory power over intermediate "quarterly" return horizons.

The dual variance concepts underlying our empirical investigations of these theoretical relations are both fairly new. On the one hand, several recent studies have argued for the use of so-called model-free realized variances computed by the summation of high-frequency intraday squared returns. These types of measures generally afford much more accurate ex post observations on the actual return variation than the more traditional sample variances based on daily or coarser frequency return observations (see, for example, Andersen et al. 2001a; Barndorff-Nielsen and Shephard 2002; Meddahi 2002). ${ }^{2}$

On the other hand, the recently developed so-called model-free implied variances provide ex ante risk-neutral expectations of the future return variation. In contrast to the standard option-implied variances based on the Black-Scholes pricing formula, or some variant thereof, the "model-free" implied variances

\footnotetext{
${ }^{1}$ For recent discussions in support of return predictability, see, for example, Lewellen (2004) and Cochrane (2008).

2 Earlier empirical studies exploring similar ideas include Schwert (1990) and Hsieh (1991).
} 
are computed from a collection of option prices without the use of a specific pricing model (see, for example, Carr and Madan 1998; Britten-Jones and Neuberger 2000; Jiang and Tian 2005).

Our main empirical finding that the difference between the "model-free" implied and realized variances is able to explain a nontrivial fraction of the variation in quarterly stock market returns over the 1990-2007 sample period is new and easily dominates that afforded by other more commonly employed predictor variables. ${ }^{3}$ Moreover, combining the variance risk premium with some of these other predictor variables, most notably the P/E ratio, results in even greater return predictability and joint significance of the predictor variables. This in turn suggests that volatility and consumption risk both play important roles in determining the returns, with their relative contributions varying across return horizons.

The plan for the rest of the paper is as follows. Section 1 outlines the basic theoretical model and corresponding predictability regressions that motivate our empirical investigations. Section 2 discusses the "model-free" implied and realized variances that we use in empirically quantifying the variance risk premium along with practical data considerations. Section 3 presents our main empirical findings and robustness checks. Section 4 concludes.

\section{Volatility in Equilibrium}

The classical intertemporal CAPM model of Merton (1973) is often used to motivate the existence of a traditional risk-return tradeoff in aggregate market returns. Despite an extensive empirical literature devoted to the estimation of such a premium, the search for a significant time-invariant expected returnvolatility tradeoff type relationship has largely proven elusive. ${ }^{4}$ In this section, we present a stylized general equilibrium model designed to illuminate new and more complex theoretical linkages between financial market volatility and expected returns. The model involves a standard endowment economy with Epstein-Zin-Weil recursive preferences. ${ }^{5}$

The basic setup builds on and extends the discrete-time long-run risk model pioneered by Bansal and Yaron (2004) by allowing for richer volatility

\footnotetext{
3 Related empirical links between stock market returns and various notions of variance risk have been informally explored by finance professionals. For example, Beckers and Bouten (2005) report that a market timing strategy based on the ratio of implied to historical volatilities doubles the Sharpe ratio relative to that of a constant S\&P 500 exposure. Many equity-oriented hedge funds also actively trade variance risk in the highly liquid OTC variance swap market (see, for example, Bondarenko 2004).

4 A significant equilibrium relationship, explicitly allowing for temporal variation in the price of risk, has recently been estimated by Bekaert, Engstrom, and Xing (2008). Also, Ang et al. (2006) find that innovations in aggregate volatility carry a statistically significant (negative) risk premium and that cross-sectionally idiosyncratic volatility is negatively related with average stock returns.

5 The Epstein and Zin (1991) and Weil (1989) preferences are rooted in the dynamic choice theory of Kreps and Porteus (1978).
} 
dynamics in the form of stochastically time-varying volatility-of-volatility. ${ }^{6}$ This in turn results in an empirically more realistic two-factor structure for the aggregate stock market volatility, and importantly suggests new and interesting channels through which the endogenously generated time-varying risk premia on consumption and volatility risk might manifest themselves empirically. To simplify the analysis and focus on the role of time-varying volatility, we explicitly exclude the long-run risk factor in consumption growth highlighted in the original Bansal and Yaron (2004) model.

\subsection{Model setup and assumptions}

To begin, suppose that the geometric growth rate of consumption in the economy, $g_{t+1}=\log \left(C_{t+1} / C_{t}\right)$, is unpredictable,

$$
g_{t+1}=\mu_{g}+\sigma_{g, t} z_{g, t+1},
$$

where $\mu_{g}$ denotes the constant mean growth rate, $\sigma_{g, t}$ refers to the conditional variance of the growth rate, and $\left\{z_{g, t}\right\}$ is an i.i.d. $\mathrm{N}(0,1)$ innovation process. ${ }^{7}$ Furthermore, assume that the volatility dynamics are governed by the following discrete-time versions of continuous-time square root-type processes,

$$
\begin{aligned}
\sigma_{g, t+1}^{2} & =a_{\sigma}+\rho_{\sigma} \sigma_{g, t}^{2}+\sqrt{q_{t}} z_{\sigma, t+1}, \\
q_{t+1} & =a_{q}+\rho_{q} q_{t}+\varphi_{q} \sqrt{q_{t}} z_{q, t+1},
\end{aligned}
$$

where the parameters satisfy $a_{\sigma}>0, a_{q}>0,\left|\rho_{\sigma}\right|<1,\left|\rho_{q}\right|<1, \varphi_{q}>0$, and $\left\{z_{\sigma, t}\right\}$ and $\left\{z_{q, t}\right\}$ are independent i.i.d. $\mathrm{N}(0,1)$ processes jointly independent of $\left\{z_{g, t}\right\}$. The stochastic volatility process $\sigma_{g, t+1}^{2}$ represents time-varying economic uncertainty in consumption growth with the volatility-of-volatility process $q_{t}$ in effect inducing an additional source of temporal variation in that same process. Both processes play a crucial role in generating the time-varying volatility risk premia discussed below. The assumption of independent innovations across all three equations explicitly rules out any return-volatility correlations that might otherwise arise via purely statistical channels. ${ }^{8}$

${ }^{6}$ Empirical evidence in support of time-varying consumption growth volatility has recently been presented by Bekaert and Liu (2004); Bansal, Khatchatrian, and Yaron (2005); Bekaert, Engstrom, and Xing (2008); and Lettau, Ludvigson, and Wachter (2008), among others.

7 The growth rate of consumption is identically equal to the dividend growth rate in this Lucas-tree economy.

${ }^{8}$ Direct estimation of the stylized model defined by Equations (1)-(3) would require the use of latent variable techniques. Instead, as a way to gauge the specification, we calculated a robust estimate for $\sigma_{g, t}^{2}$ by exponentially smoothing the squared (de-meaned) growth rate in U.S. real expenditures on nondurable goods and services $\left(g_{t}-\hat{\mu_{g}}\right)^{2}$ over the 1947:Q2 to 2007:Q4 sample period using a smoothing parameter of 0.06. Consistent with the basic model structure in Equation (2), the serial dependencies in the resulting $\hat{\sigma}_{g, t}^{2}$ series appear to be well described by an $\operatorname{AR}(1)$ model with $\rho_{\sigma}$ close to unity. Consistent with the Great Moderation, the variances are generally also much lower over the latter part of the sample. Moreover, on estimating an AR(1)-GARCH(1,1) model for $\hat{\sigma}_{g, t}^{2}$, the estimates for the two GARCH parameters equal 0.238 and 0.655 , respectively, and the Wald test for their joint significance and the absence of any ARCH effects (129.9) has a $p$-value of virtually zero, thus strongly supporting the notion of time-varying volatility-of-volatility in consumption growth or $\operatorname{Var}\left(q_{t}\right)>0$. 
We assume that the representative agent in the economy is equipped with Epstein-Zin-Weil recursive preferences. Consequently, the logarithm of the intertemporal marginal rate of substitution, $m_{t+1} \equiv \log \left(M_{t+1}\right)$, may be expressed as

$$
m_{t+1}=\theta \log \delta-\theta \psi^{-1} g_{t+1}+(\theta-1) r_{t+1},
$$

where

$$
\theta \equiv(1-\gamma)\left(1-\psi^{-1}\right)^{-1}
$$

$\delta$ denotes the subjective discount factor, $\psi$ equals the intertemporal elasticity of substitution, $\gamma$ refers to the coefficient of risk aversion, and $r_{t+1}$ is the time $t$ to $t+1$ return on the consumption asset. We will maintain the assumptions that $\gamma>1$ and $\psi>1$, which in turn implies that $\theta<0 .{ }^{9}$ These restrictions ensure, among other things, that volatility carries a positive risk premium, and that asset prices fall on news of positive volatility shocks consistent with the socalled leverage effect. Importantly, these effects are not the result of any direct statistical linkages between return and volatility, but instead arise endogenously within the model.

\subsection{Model solution and equity premium}

Let $w_{t}$ denote the logarithm of the price-dividend ratio, or equivalently the price-consumption or wealth-consumption ratio, of the asset that pays the consumption endowment, $\left\{C_{t+i}\right\}_{i=1}^{\infty}$. The standard solution method for finding the equilibrium in a model like the one defined above then consists in conjecturing a solution for $w_{t}$ as an affine function of the state variables, $\sigma_{g, t}^{2}$ and $q_{t}$,

$$
w_{t}=A_{0}+A_{\sigma} \sigma_{g, t}^{2}+A_{q} q_{t},
$$

solving for the coefficients $A_{0}, A_{\sigma}$, and $A_{q}$, using the standard Campbell and Shiller (1988) approximation $r_{t+1}=\kappa_{0}+\kappa_{1} w_{t+1}-w_{t}+g_{t+1}$. The resulting equilibrium solutions for the three coefficients may be expressed as

$$
\begin{aligned}
& A_{0}=\frac{\log \delta+\left(1-\psi^{-1}\right) \mu_{g}+\kappa_{0}+\kappa_{1}\left[A_{\sigma} a_{\sigma}+A_{q} a_{q}\right]}{\left(1-\kappa_{1}\right)}, \\
& A_{\sigma}=\frac{(1-\gamma)^{2}}{2 \theta\left(1-\kappa_{1} \rho_{\sigma}\right)}, \\
& A_{q}=\frac{1-\kappa_{1} \rho_{q}-\sqrt{\left(1-\kappa_{1} \rho_{q}\right)^{2}-\theta^{2} \kappa_{1}^{4} \varphi_{q}^{2} A_{\sigma}^{2}}}{\theta \kappa_{1}^{2} \varphi_{q}^{2}}
\end{aligned}
$$

9 The assumption that $\gamma>1$ is generally agreed upon, but the assumption that $\psi>1$ is a matter of some debate (see, for example, the discussion in Bansal and Yaron 2004). 
The aforementioned restrictions that $\gamma>1$ and $\psi>1$ readily imply that the impact coefficients associated with both of the volatility state variables are negative, i.e., $A_{\sigma}<0$ and $A_{q}<0 .{ }^{10}$

From the solution for the $A$ 's, it is now relatively straightforward to deduce the reduced form expressions for other variables of interest. In particular, the time $t$ to $t+1$ return must satisfy the following relation:

$$
\begin{aligned}
r_{t+1}= & -\log \delta+\psi^{-1} \mu_{g}-\frac{(1-\gamma)^{2}}{2 \theta} \sigma_{g, t}^{2}+\left(\kappa_{1} \rho_{q}-1\right) A_{q} q_{t} \\
& +\sigma_{g, t} z_{g, t+1}+\kappa_{1} \sqrt{q_{t}}\left[A_{\sigma} z_{\sigma, t+1}+A_{q} \varphi_{q} z_{q, t+1}\right] .
\end{aligned}
$$

As is evident, increases in endowment volatility, $\sigma_{g, t}^{2}$, and the volatility-ofvolatility, $q_{t}$, both increase the return reflecting the compensation for bearing volatility risk. On the other hand, innovations in future volatility, $z_{\sigma, t+1}$ and $z_{q, t+1}$, both impact the return negatively, consistent with a leverage-type effect.

To further appreciate the implications of richer time-varying volatility dynamics, it is instructive to consider the model-implied equity premium, $\pi_{r, t} \equiv-\operatorname{Cov}_{t}\left(m_{t+1}, r_{t+1}\right)$,

$$
\pi_{r, t}=\gamma \sigma_{g, t}^{2}+(1-\theta) \kappa_{1}^{2}\left(A_{q}^{2} \varphi_{q}^{2}+A_{\sigma}^{2}\right) q_{t} .
$$

The premium is composed of two separate terms. The first term, $\gamma \sigma_{g, t}^{2}$, motivates the classic risk-return tradeoff relationship, which has undergone extensive yet empirically elusive investigations. The term does not really represent a volatility risk premium per se, however. Instead, it arises within the model as the presence of time-varying volatility in effect induces shifts in the price of consumption risk. The second term, $(1-\theta) \kappa_{1}^{2}\left(A_{q}^{2} \varphi_{q}^{2}+A_{\sigma}^{2}\right) q_{t}$, represents a true premium for volatility risk. ${ }^{11}$ It is a confounding of a risk premium on shocks to volatility, $z_{\sigma, t+1}$, and shocks to the volatility-of-volatility, $z_{q, t+1}$. As such, it represents a fundamentally different source of risk from that of the traditional consumption risk term. The existence of the volatility risk premium depends crucially on the dual assumptions of recursive utility, or $\theta \neq 1$, as volatility would otherwise not be a priced factor and time-varying volatility-of-volatility in the form of the $q_{t}$ process. This additional source of uncertainty is absent in the model of Bansal and Yaron (2004). The restrictions that $\gamma>1$ and $\psi>1$ imply that the volatility risk premium is positive.

\subsection{Volatility risk and return predictability}

The expression for the equity premium in Equation (11) provides a direct relationship between the expected excess equilibrium return and the two volatility

10 The solution for $A_{q}$ in Equation (9) represents one of a pair of roots to a quadratic equation, but it is the economically meaningful root for reasons discussed below.

11 The specific root in Equation (9) implies that $A_{q}^{2} \varphi_{q}^{2} \rightarrow 0$ for $\varphi_{q} \rightarrow 0$, which guarantees that the premium disappears when $q_{t}$ is constant as would be required by the lack of arbitrage. 
factors, $\sigma_{g, t}^{2}$ and $q_{t}$. Both of these factors are inherently latent. Importantly, however, each of the factors manifests itself differently in different volatility concepts that are naturally defined within the model. In particular, the difference between the actual and the risk-neutral expected variance effectively isolates the $q_{t}$ factor, which as explained above constitutes the source of the true volatility risk premium.

To formally establish this result, denote the conditional variance of the time $t$ to $t+1$ return as $\sigma_{r, t}^{2} \equiv \operatorname{Var}_{t}\left(r_{t+1}\right)$. It follows from Equation (10) that

$$
\sigma_{r, t}^{2}=\sigma_{g, t}^{2}+\kappa_{1}^{2}\left(A_{\sigma}^{2}+A_{q}^{2} \varphi_{q}^{2}\right) q_{t},
$$

which is directly influenced by each of the two stochastic factors, the underlying economic volatility, $\sigma_{g, t}^{2}$, and the volatility of that volatility, $q_{t}$. This conditional variance is, of course, known at time $t$. Consider instead the one-period ahead conditional variance,

$$
\sigma_{r, t+1}^{2}=\sigma_{g, t+1}^{2}+\kappa_{1}^{2}\left(A_{\sigma}^{2}+A_{q}^{2} \varphi_{q}^{2}\right) q_{t+1},
$$

which is unknown or stochastic at time $t$. The difference between the objective and risk-neutral expectations of $\sigma_{r, t+1}^{2}$ as of time $t$ will depend upon the way in which volatility risk is priced.

It follows readily that the time $t$ objective conditional expectation equals

$$
E_{t}\left(\sigma_{r, t+1}^{2}\right)=a_{\sigma}+\kappa_{1}^{2}\left(A_{\sigma}^{2}+A_{q}^{2} \varphi_{q}^{2}\right) a_{q}+\rho_{\sigma} \sigma_{g, t}^{2}+\kappa_{1}^{2}\left(A_{\sigma}^{2}+A_{q}^{2} \varphi_{q}^{2}\right) \rho_{q} q_{t} .
$$

The corresponding model-implied risk-neutral conditional expectation $E_{t}^{Q}\left(\sigma_{r, t+1}^{2}\right) \equiv E_{t}\left(\sigma_{r, t+1}^{2} M_{t+1}\right) E_{t}\left(M_{t+1}\right)^{-1}$ cannot easily be computed in a closed form. However, it is possible to calculate the following close log-linear approximation:

$$
\begin{aligned}
E_{t}^{Q}\left(\sigma_{r, t+1}^{2}\right) & \approx \log \left[e^{-r_{f, t}} E_{t}\left(e^{m_{t+1}+\sigma_{r, t+1}^{2}}\right)\right]-\frac{1}{2} \operatorname{Var}_{t}\left(\sigma_{r, t+1}^{2}\right) \\
& =E_{t}\left(\sigma_{r, t+1}^{2}\right)+(\theta-1) \kappa_{1}\left[A_{\sigma}+A_{q} \kappa_{1}^{2}\left(A_{\sigma}^{2}+A_{q}^{2} \varphi_{q}^{2}\right) \varphi_{q}^{2}\right] q_{t}
\end{aligned}
$$

where $r_{f, t}$ denotes the one-period risk-free rate implied by the model. A number of interesting implications arise from comparing these two different expectations of the same future variance.

In particular, any temporal variation in the endogenously generated variance risk premium,

$$
E_{t}^{Q}\left(\sigma_{r, t+1}^{2}\right)-E_{t}\left(\sigma_{r, t+1}^{2}\right)=(\theta-1) \kappa_{1}\left[A_{\sigma}+A_{q} \kappa_{1}^{2}\left(A_{\sigma}^{2}+A_{q}^{2} \varphi_{q}^{2}\right) \varphi_{q}^{2}\right] q_{t},
$$

is solely due to the volatility-of-volatility or $q_{t}$. Moreover, provided that $\theta<0$, $A_{\sigma}<0$, and $A_{q}<0$, as would be implied by $\gamma>1$ and $\psi>1$, this difference between the risk-neutral and objective expected variation is guaranteed to be positive. If $\varphi_{q}=0$, and therefore $q_{t}=q$ is constant, the variance premium 
reduces to

$$
E_{t}^{Q}\left(\sigma_{r, t+1}^{2}\right)-E_{t}\left(\sigma_{r, t+1}^{2}\right)=(\theta-1) \kappa_{1} A_{\sigma} q,
$$

which, of course, would also be constant. Comparing the expression in Equation (16) to the expression for the equity premium in Equation (11) suggests that the variance risk premium should serve as a useful predictor for the actual realized returns over horizons for which the volatility-of-volatility or $q_{t}$ constitutes the dominant source of the variation in the equity premium. For highly persistent volatility dynamics, or $\rho_{\sigma} \approx 1$, the objective expected future volatility will obviously be close to the value of the current volatility so that the same qualitative implications hold true for the variance difference obtained by replacing $E_{t}\left(\sigma_{r, t+1}^{2}\right)$ in Equation (16) with the current variance.

There is also an implicit positive volatility risk-return tradeoff embedded in the solution of our stylized equilibrium model. Specifically, the reduced form Equation (11) for the risk premium, $\pi_{t}$, and Equation (12) for the conditional variance, $\sigma_{r, t}^{2}$, implicitly entails a positive association between return volatility and the risk premium. ${ }^{12}$ This association corresponds very closely to that of the first-order term in Corollary 3.5 of Ang and Liu (2007), who note that a positive volatility risk-return relationship can arise in models with first-order risk aversion parameterized by the Epstein-Zin-Weil recursive preferences. ${ }^{13}$

As is well known, however, empirical efforts aimed at documenting a significant positive association between the risk premium and stock price volatility have met with mixed success at best. The relationship is often statistically insignificant or even estimated to be negative. These conflicting findings have been obtained with many different data sets, estimation techniques, and control variables with no single robust empirical consensus emerging; Ang and Liu (2007) contains a recent thorough discussion of the most important studies. In the empirical results reported below, we also find that expected excess returns are insignificantly related to current volatility. Apparently, in the actual data, factor loadings of equations such as (11)-(12) along with higher-order nonlinearities and measurement problems serve to mask the expected positive association between the risk premium and stock price volatility. ${ }^{14}$

At the same time, the preceding theoretical analysis motivates our new approach based on information from derivatives markets (or $Q$-measure information) for better estimating the so far elusive risk-return tradeoff. From Equation (16), the variance difference $E_{t}^{Q}\left(\sigma_{r, t+1}^{2}\right)-E_{t}\left(\sigma_{r, t+1}^{2}\right)$ is directly related to the volatility-of-volatility factor, $q_{t}$, which appears in the expression

12 It is not exactly the same, as Ang and Liu (2007) examine a model with prespecified dynamics for a conditional standard deviation, while our model prespecifies the dynamics of the conditional variance. Nonetheless, the economic intuition behind the effects of the recursive preferences is essentially the same.

13 Keep in mind that we always assume that $\psi>0$ and $\gamma>1$, implying that $\theta<0$. The risk return relationship could be negative under other parameter values.

14 Our log-linear approximation used to solve the model excludes the higher-order effects described by Ang and Liu (2007), which they show can cloud the volatility risk-return tradeoff. 
(11) for the risk premium. As discussed below, the use of derivatives market data allows us to directly measure $E_{t}^{Q}\left(\sigma_{r, t+1}^{2}\right)$. Thus, using the derivatives data to get $E_{t}^{Q}\left(\sigma_{r, t+1}^{2}\right)$ along with empirical proxies for the actual volatility, we can potentially get a "cleaner" measure of the factor that drives the volatility risk premium, in turn allowing for more precise empirical estimation of a risk-return tradeoff relationship.

The equilibrium model underlying these return-volatility relations is somewhat stylized and not rich enough to be estimated directly with actual data. Nonetheless, it is still useful to consider the implications from a calibrated version of the theoretical model to help guide and interpret our subsequent empirical reduced form predictability regressions.

\subsection{Calibrated return regressions}

The difference between the risk-neutral expected and actual variances underlying our key empirical findings naturally corresponds to $E_{t}^{Q}\left(\sigma_{r, t+1}^{2}\right)-\sigma_{r, t-1}^{2}$ within the discrete-time theoretical model. In the regressions discussed below, both of our directly observable variance measures span one month, and we correspondingly refer to the unit time interval in the calibrated equilibrium model as a "month." In addition to the basic "monthly" return horizon, we also consider longer (scaled by the horizon) multi-period return regressions of the form

$$
\frac{1}{h} \sum_{j=1}^{h} r_{t+j}=b_{0}(h)+b_{1}(h)\left(E_{t}^{Q}\left(\sigma_{r, t+1}^{2}\right)-\sigma_{r, t-1}^{2}\right)+u_{t+h, t} .
$$

The slope coefficient,

$$
b_{1}(h)=\frac{\operatorname{Cov}\left(\frac{1}{h} \sum_{j=1}^{h} r_{t+j}, E_{t}^{Q}\left(\sigma_{r, t+1}^{2}\right)-\sigma_{r, t-1}^{2}\right)}{\operatorname{Var}\left(E_{t}^{Q}\left(\sigma_{r, t+1}^{2}\right)-\sigma_{r, t-1}^{2}\right)},
$$

and the explanatory power, as measured by the coefficient of determination,

$$
R^{2}(h)=\frac{\operatorname{Cov}\left(\frac{1}{h} \sum_{j=1}^{h} r_{t+j}, E_{t}^{Q}\left(\sigma_{r, t+1}^{2}\right)-\sigma_{r, t-1}^{2}\right)^{2}}{\operatorname{Var}\left(\frac{1}{h} \sum_{j=1}^{h} r_{t+j}\right) \operatorname{Var}\left(E_{t}^{Q}\left(\sigma_{r, t+1}^{2}\right)-\sigma_{r, t-1}^{2}\right)},
$$

from this regression are both directly related to the latent $q_{t}$ process and how the persistence and magnitude of that process compare to that of the other risk factors. The actual numerical values of the two variances and the covariance, and in turn the model-implied $b_{1}(h)$ and $R^{2}(h)$, obviously depend upon the specific values of the parameters in Equations (1)-(6). The variance of the 

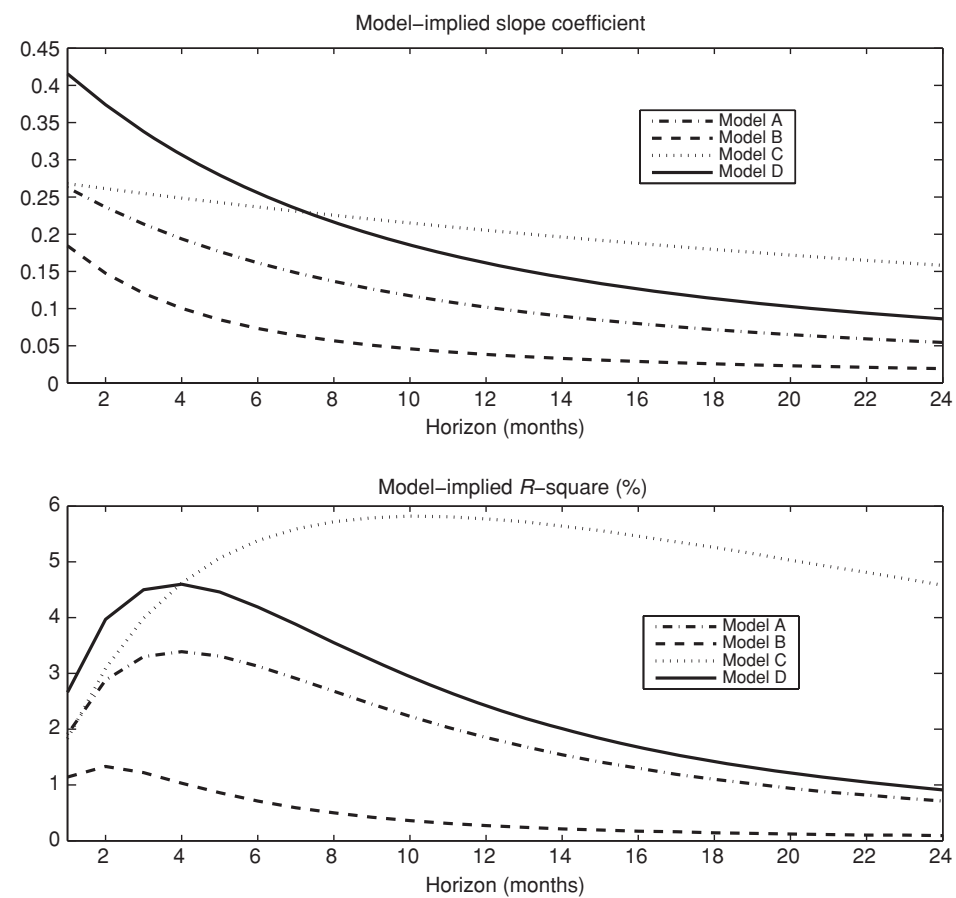

Figure 1

Model-implied slopes and $R^{2}$ s

The figure shows the population slope coefficients and $R^{2} \mathrm{~s}$ from regressions of the scaled $h$-period returns on the variance difference implied by the equilibrium model. The four different lines refer to the four different parameter configurations discussed in the main text.

multi-period returns and the covariance of those returns with the variance premium furthermore depend nontrivially on the return horizon, $h .^{15}$

To gauge more directly how the predictability varies with the model parameters and $h$, we plot in Figure 1 the population $b_{1}(h)$ 's and $R^{2}(h)$ 's for

15 Tedious calculations yield

$$
\begin{aligned}
R^{2}(h)= & \left(\frac{1-\theta}{\theta} A_{q}\left(1-\kappa_{1} \rho_{q}\right) \kappa_{1}\left[\frac{(1-\gamma)^{2}}{2\left(1-\kappa_{1} \rho_{\sigma}\right)}+2 A_{q}^{2} \varphi_{q}^{2}\left(1-\kappa_{1} \rho_{q}\right)\right] \operatorname{Var} q \frac{1-\rho_{q}^{h}}{1-\rho_{q}}\right)^{2} \\
& \times\left[\left(\frac{\theta-1}{\theta} \kappa_{1}\right)^{2}\left[\frac{(1-\gamma)^{2}}{2\left(1-\kappa_{1} \rho_{\sigma}\right)}+2 A_{q}^{2} \varphi_{q}^{2}\left(1-\kappa_{1} \rho_{q}\right)\right]^{2} \operatorname{Var} q+\left(1-\rho_{q}^{2}\right) \operatorname{Var} q+\left(1-\rho_{\sigma}^{2}\right) \operatorname{Var}_{g}^{2}\right]^{-1} \\
& \times\left[\frac{h a_{q}}{1-\rho_{\sigma}}+\left[\frac{\left(1-\kappa_{1}\right)^{2}}{\left(1-\rho_{\sigma}\right)^{2}}\left(h\left(1-\rho_{\sigma}^{2}\right)+4 \rho_{\sigma}^{h+1}-2 \rho_{\sigma}^{h}-2 \rho_{\sigma}^{2}\right)+\left(1-2 \rho_{\sigma}^{h} \kappa_{1}+\kappa_{1}^{2}\right)\right] \operatorname{Var} \sigma_{g}^{2}\right. \\
& \left.+\left[\frac{\left(1-\kappa_{1}\right)^{2}}{\left(1-\rho_{q}\right)^{2}}\left(h\left(1-\rho_{q}^{2}\right)+4 \rho_{q}^{h+1}-2 \rho_{q}^{h}-2 \rho_{q}^{2}\right)+\left(1-2 \rho_{q}^{h} \kappa_{1}+\kappa_{1}^{2}\right)\right] \operatorname{Var} q\right]^{-1},
\end{aligned}
$$

where $\operatorname{Var}_{g}^{2}=a_{q}\left(1-\rho_{q}\right)^{-1}\left(1-\rho_{\sigma}^{2}\right)^{-1}$ and $\operatorname{Var} q=\phi_{q}^{2} a_{q}\left(1-\rho_{q}^{2}\right)^{-1}\left(1-\rho_{\sigma}^{2}\right)^{-1}$. The corresponding formula for the slope coefficient $b_{1}(h)$ follows readily from this expression. 
four different parameter configurations and return horizons ranging from "one month" $(h=1)$ to "two years" $(h=24)$. The values for $\delta=0.997, \gamma=10.0$, $\psi=1.5, \mu_{g}=0.0015$, and $E\left(\sigma_{g}\right)=0.0078$ in the baseline model (Model A) are all adapted directly from Bansal and Yaron (2004). Additionally, we fix $\kappa_{1}=0.9$, the persistence of the variance at $\rho_{\sigma}=0.978$, the persistence of the volatility-of-volatility at $\rho_{q}=0.8$, the expected volatility-of-volatility at $a_{q}\left(1-\rho_{q}\right)^{-1}=10.0^{-6}$, and the volatility of that process at $\phi_{q}=10.0^{-3}$. The mean annualized risk-free rate and equity premium implied by these particular model parameters equal $0.69 \%$ and $7.79 \%$, respectively.

The model-implied slope coefficients depicted in the top panel of Figure 1 all decline monotonically with the return horizon. For the baseline model (Model A), $b_{1}(h)$ starts out at 0.26 declining to 0.10 at the annual horizon. Decreasing (increasing) the persistence in the $q_{t}$ process from $\rho_{q}=0.8$ to 0.6 (0.95), keeping all of the other model parameters the same as in Model B (Model C) results in systematically lower (higher) population slope coefficients. Increasing the value of the intertemporal elasticity of substitution from $\psi=1.5$ to 2.5 (Model D) magnifies the relation between the returns and the variance risk premium and results in systematically higher $b_{1}(h)$ 's across all return horizons.

Turning to the model-implied $R^{2}(h)$ 's depicted in the bottom panel in the figure, the degree of predictability for the baseline model (Model A) starts out fairly low at the "monthly" horizon, rising to its maximum around a "quarter," gradually tapering off thereafter for longer return horizons. In line with the results for the slope coefficients, lowering the degree of persistence in the $q_{t}$ process to $\rho_{q}=0.6$ (Model B) results in substantially lower overall predictability, and also shifts the peak in the $R^{2}(h)$ 's from a "quarter" to "two months." Conversely, increasing the persistence to $\rho_{q}=0.95$ (Model C) increases the relative importance of stochastically varying volatility-of-volatility and prolongs the inherent return predictability. Lastly, changing the value of the intertemporal elasticity of substitution from $\psi=1.5$ to 2.5 (Model D) enhances the importance of time-varying volatility-of-volatility and increases the $R^{2}(h)$ 's relative to those for the baseline model (Model A), with the maximum again occurring around the "quarterly" return horizon.

As these calibrations make clear, the simple stylized general equilibrium model can give rise to quite sizable regression coefficients and return predictability. Importantly, the calibrations also reveal a general hump shape in the implied $R^{2}$ as a function of the return horizon with the location of the peak directly related to the value of $\rho_{q}$. At an intuitive level, the variance risk premium or the "variance swap" on the right-hand side of the regression, $E_{t}^{Q}\left(\sigma_{r, t+1}^{2}\right)-\sigma_{r, t-1}^{2}$, may be seen as a pure volatility bet where everything else gets "risk neutralized" out. Since volatility is explicitly priced under the Epstein-Zin-Weil recursive preference structure, this variance difference earns exactly that volatility risk premium and nothing else. The price of this risk changes if the variance of the priced factor changes. But this corresponds exactly to the volatility-of-volatility or the $q_{t}$ process within the theoretical model. 
We next turn to a discussion of the procedures and data that we actually use in empirically quantifying the $E_{t}^{Q}\left(\sigma_{r, t+1}^{2}\right)$ and $\sigma_{r, t}^{2}$ variance measures.

\section{Empirical Measurements}

The theoretical model outlined in the previous section suggests that the difference between current return variation and the market's risk-neutral expectation of future return variation may serve as a useful predictor for the future returns by effectively isolating the systematic risk associated with the volatility-ofvolatility. To measure the variance risk premium and investigate this conjecture, we rely on two relatively new nonparametric "model-free" variation concepts.

\subsection{Model-free variation measures}

To formally define the procedure that we use in quantifying the market's expected return variation, let $C_{t}(T, K)$ denote the price of a European call option maturing at time $T$ with strike price $K$, and let $B(t, T)$ denote the price of a time $t$ zero-coupon bond maturing at time $T$. As shown by Carr and Madan (1998); Demeterfi et al. (1999); and Britten-Jones and Neuberger (2000), the market's risk-neutral expectation of the total return variation between time $t$ and $t+1$ conditional on time $t$ information, or the implied variance $I V_{t}$, may then be expressed in a "model-free" fashion as the following portfolio of European calls:

$$
\begin{aligned}
I V_{t} & \equiv 2 \int_{0}^{\infty} \frac{C_{t}\left(t+1, \frac{K}{B(t, t+1)}\right)-C_{t}(t, K)}{K^{2}} d K \\
& =E_{t}^{Q}[\text { Return variation }(t, t+1)],
\end{aligned}
$$

which relies on an ever-increasing number of calls with strikes spanning zero to infinity. ${ }^{16}$ This "model-free" measure therefore provides a natural empirical analog to $E_{t}^{Q}\left(\sigma_{r, t+1}^{2}\right)$ in the discrete-time model discussed in the previous section. In practice, of course, $I V_{t}$ must be constructed on the basis of a finite number of strikes. Fortunately, even with relatively few different options, this tends to provide a fairly accurate approximation to the true (unobserved) risk-neutral expectation of the future return variation, and, in particular, a much better approximation than the one based on inversion of the standard Black-Scholes formula with close to at-the-money option(s) (see, for example, Jiang and Tian 2005; Bollerslev, Gibson, and Zhou 2006).

In order to define the measure that we use in quantifying the actual return variation, let $p_{t}$ denote the logarithmic price of the asset. The realized variation over the discrete $t-1$ to $t$ time interval may then be measured in a "model-free"

16 See Bondarenko (2004); Jiang and Tian (2005); and Carr and Wu (2009) for justification under the assumption of general jump-diffusion processes. 
fashion by

$$
R V_{t} \equiv \sum_{j=1}^{n}\left[p_{t-1+\frac{j}{n}}-p_{t-1+\frac{j-1}{n}(\Delta)}\right]^{2} \longrightarrow \text { Return variation }(t-1, t)
$$

where the convergence relies on $n \rightarrow \infty$, i.e., an increasing number of withinperiod price observations. As demonstrated in the literature (see, for example, Andersen et al. 2001a, 2001b; Barndorff-Nielsen and Shephard 2002; Meddahi 2002), this "model-free" realized variance measure based on high-frequency intraday data affords much more accurate ex post observations of the true (unobserved) return variation than do the more traditional sample variances based on daily or coarser frequency returns. It also provides a nonparametric empirical analog to $\sigma_{r, t}^{2}$ in the discrete-time model in the previous section. In practice, of course, as discussed below, various market microstructure frictions invariably limit the highest sampling frequency that may be used in reliably estimating $R V_{t}$.

The variance risk premium or difference underlying our key empirical findings is defined by the difference between this ex ante risk-neutral expectation of the future return variation over the $[t, t+1]$ time interval and the ex post realized return variation over the $[t-1, t]$ time interval,

$$
V R P_{t} \equiv I V_{t}-R V_{t}
$$

affording a "model-free" empirical equivalent to the variance difference on the right-hand side in the regression Equation (17). Compared to the variance premium in Equation (16), the variance difference has the advantage that $I V_{t}$ and $R V_{t}$, and therefore $V R P_{t}$, are directly observable at time $t$. This is obviously important from a forecasting perspective. However, we also briefly discuss below complimentary empirical results in which we regress the returns on an estimate for the expected premium, $E V R P_{t} \equiv I V_{t}-E_{t}\left(R V_{t+1}\right)$, in which we approximate $E_{t}\left(R V_{t+1}\right)$ by the one-step-ahead forecasts from a simple reduced form time-series model for $R V_{t}$. Of course, the two premia trivially coincide under the assumption that $R V_{t}$ is a martingale difference sequence or $E_{t}\left(R V_{t+1}\right)=R V_{t}$ corresponding to $\rho_{\sigma}=1$ in the stylized discrete-time theoretical model developed in the previous section.

Closely related measures of variance risk premia have recently been investigated from different empirical perspectives in other studies. In particular, Bollerslev, Gibson, and Zhou (2006) find that the temporal variation in a measure of $E V R P_{t}$ for the aggregate market portfolio, as implied by a standard Heston (1993) one-factor stochastic volatility model, may, in part, be explained by a set of macrofinance variables, including some of the more traditional predictor variables considered below. Similarly, Todorov (2007) has explored the joint dynamics of $I V_{t}$ and $E_{t}\left(R V_{t+1}\right)$ within the context of a very general continuous time specification allowing for separate jump and diffusive risk 
premiums. The difference between implied and realized variance measures has also previously been associated empirically with notions of aggregate market risk aversion by Rosenberg and Engle (2002), while Bakshi and Madan (2006) have formally shown that the volatility spread may be expressed as a nonlinear function of the aggregate degree of risk aversion in a simple representative agent setting.

\subsection{Data description}

Our empirical analysis is based on the aggregate S\&P 500 composite index as a proxy for the aggregate market portfolio. Due to the dual requirements of reliable high-frequency data and options-implied volatilities, our sample "only" spans the period from January 1990 to December 2007.

We rely on monthly data for the "new" VIX index for quantifying $I V_{t}$. The VIX index is based on the highly liquid S\&P 500 index options along with the "model-free" approach discussed above explicitly tailored to replicate the risk-neutral variance of a fixed 30-day maturity. The data are obtained directly from the Chicago Board of Options Exchange (CBOE). ${ }^{17}$ The VIX index is invariably subject to some approximation error (see, for example, the discussion in Jiang and Tian 2007), but the CBOE procedure for calculating the VIX has arguably emerged as the industry standard. Thus, in order to facilitate replication and comparison with other studies, we purposely rely on the readily available squared VIX index as our measure for the risk-neutral expected variance.

The intraday data for the S\&P 500 composite index that we use in the construction of our "model-free" $R V_{t}$ measure is provided by the Institute of Financial Markets. The theory behind the realized variation measures dictates that the sampling frequency, or $n$ in the expression for $R V_{t}$ above, goes to infinity. However, a host of practical market microstructure features, including price discreteness, bid-ask spreads, and nonsynchronous trading effects, imply that the underlying semimartingale assumption for the returns is violated at the very highest sampling frequencies. In practice, it therefore becomes necessary to strike a balance between the desire to use very finely sampled data to minimize the estimation error on the one hand and not be overwhelmed by "noise" in the high-frequency prices on the other. A number of studies, using the volatility signature plot first proposed by Andersen et al. (2000), suggest that for highly liquid assets, such as the S\&P 500 index analyzed here, a fiveminute sampling frequency provides a reasonable choice (see, for example, the discussion in Hansen and Lunde 2006). Following this recommendation, we base our monthly realized variance measure for the S\&P 500 on the summation

17 The CBOE replaced the "old" VIX index, based on S\&P 100 options and Black-Scholes implied volatilities, with the "new" VIX index based on S\&P 500 options and "model-free" implied volatilities in September 2003. Historical data on both indexes are available from the official CBOE Web site. A more detailed description of the procedure actually used in approximating the integral in the calculation of the VIX is provided in the White Paper on the CBOE Web site. 
S\&P 500 implied variance

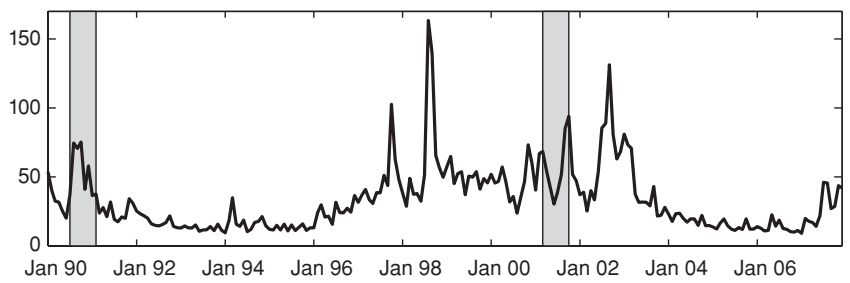

S\&P 500 realized variance

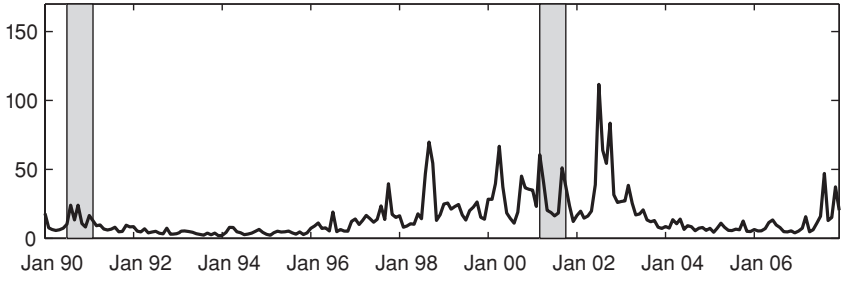

Difference between implied and realized variances

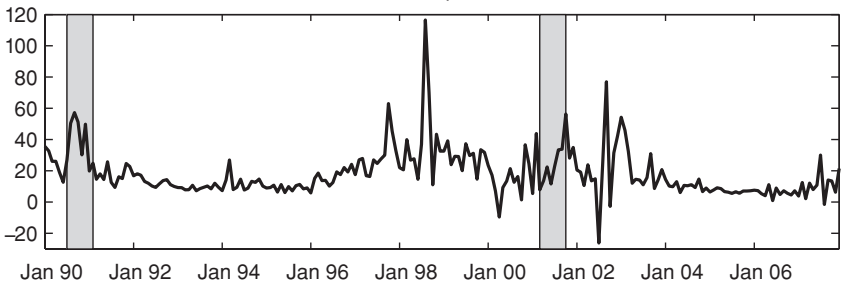

Figure 2

Implied and realized variances and variance risk premium

This figure plots the implied variance (the top panel), the realized variance (the middle panel), and the difference (the bottom panel) for the S\&P 500 market index from January 1990 to December 2007. The shaded areas represent NBER recessions.

of the 78 within-day five-minute squared returns covering the normal trading hours from 9:30 am to 4:00 pm along with the close-to-open overnight return. ${ }^{18}$ For a typical month with 22 trading days, this leaves us with a total of $n=$ $22 \times 78=1716$ "five-minute" returns.

To illustrate the data, Figure 2 plots the monthly time series of implied variances, realized variances, and their differences. Both of the variance measures are somewhat higher during the 1997-2002 part of the sample. The more distinct spikes in the measures generally also coincide. Consistent with the theoretical model developed in the previous section and the earlier empirical evidence cited above, the spread between the implied and realized variances is almost always positive.

18 Recent studies (for example, Zhang, Mykland, and Aït-Sahalia 2005; Barndorff-Nielsen et al. 2008) have proposed more efficient and complicated ways in which to accommodate the market microstructure effects that allow for finer sampling. However, the simple-to-implement $R V_{t}$ estimator based on the summation of (not too finely sampled) high-frequency squared returns that we rely on here remains the dominant method in practical applications. 
Table 1

Summary statistics

$R_{m t}-R_{f t} I V_{t}-R V_{t} \quad I V_{t} \quad R V_{t} \quad \log \left(P_{t} / E_{t}\right) \log \left(P_{t} / D_{t}\right) \quad D_{F S P_{t}}$ TMSP $_{t} \quad R_{R E L_{t}} \quad C A Y_{t}$

\begin{tabular}{|c|c|c|c|c|c|c|c|c|c|c|}
\hline \multirow[b]{2}{*}{ Mean } & \multicolumn{10}{|c|}{ Summary statistics } \\
\hline & 6.44 & 18.30 & 33.23 & 14.93 & 3.13 & 3.92 & 0.84 & 1.69 & -0.11 & 0.33 \\
\hline Std. dev. & 47.19 & 15.13 & 23.73 & 15.25 & 0.26 & 0.34 & 0.20 & 1.19 & 0.78 & 1.80 \\
\hline Skewness & -0.65 & 2.14 & 2.02 & 2.72 & 0.42 & -0.19 & 0.90 & 0.09 & -0.35 & -0.09 \\
\hline Kurtosis & 4.38 & 12.06 & 9.11 & 12.98 & 2.44 & 1.98 & 3.28 & 1.79 & 2.75 & 1.94 \\
\hline \multirow[t]{2}{*}{$\mathrm{AR}(1)$} & -0.03 & 0.49 & 0.79 & 0.70 & 0.97 & 0.99 & 0.94 & 0.98 & 0.94 & 0.96 \\
\hline & \multicolumn{10}{|c|}{ Correlation matrix } \\
\hline$R_{m t}-R_{f t}$ & 1.00 & -0.30 & -0.34 & -0.23 & -0.08 & -0.07 & -0.05 & -0.02 & 0.00 & -0.05 \\
\hline$I V_{t}-R V_{t}$ & & 1.00 & 0.78 & 0.22 & 0.19 & 0.11 & 0.10 & -0.08 & -0.27 & -0.04 \\
\hline$I V_{t}$ & & & 1.00 & 0.78 & 0.41 & 0.35 & 0.26 & -0.14 & -0.31 & -0.21 \\
\hline$R V_{t}$ & & & & 1.00 & 0.45 & 0.44 & 0.31 & -0.14 & -0.21 & -0.30 \\
\hline $\log \left(P_{t} / E_{t}\right)$ & & & & & 1.00 & 0.65 & 0.25 & 0.29 & -0.24 & -0.59 \\
\hline $\log \left(P_{t} / D_{t}\right)$ & & & & & & 1.00 & -0.03 & -0.36 & 0.09 & -0.87 \\
\hline$D F S P_{t}$ & & & & & & & 1.00 & 0.21 & -0.43 & -0.03 \\
\hline$T M S P_{t}$ & & & & & & & & 1.00 & -0.36 & 0.35 \\
\hline$R R E L_{t}$ & & & & & & & & & 1.00 & -0.18 \\
\hline$C A Y_{t}$ & & & & & & & & & & 1.00 \\
\hline
\end{tabular}

The sample period extends from January 1990 to December 2007. All variables are reported in annualized percentage form whenever appropriate. The $R_{m t}-R_{f t}$ denotes the logarithmic return on the S\&P 500 in excess of the three-month T-bill rate. $I V_{t}$ denotes the "model-free" implied variance or VIX index. $R V_{t}$ refers to the "modelfree" realized variance constructed from high-frequency five-minute returns. The predictor variables include the price-earning ratio $\log \left(P_{t} / E_{t}\right)$, the price-dividend ratio $\log \left(P_{t} / D_{t}\right)$, the default spread $D F S P_{t}$ defined as the difference between Moody's BAA and AAA bond yield indices, the term spread $T M S P_{t}$ defined as the difference between the ten-year and three-month Treasury yields, and the stochastically detrended risk-free rate $R R E L_{t}$ defined as the one-month T-bill rate minus its trailing twelve-month moving averages. Monthly observations on the consumption-wealth ratio $C A Y_{t}$ are defined by the most recently available quarterly observations.

In addition to the variance risk premium, we also consider a set of other more traditional predictor variables (see, for example, Lamont 1998; Lettau and Ludvigson 2001; Ang and Bekaert 2007). Specifically, we obtain monthly $\mathrm{P} / \mathrm{E}$ ratios and dividend yields for the S\&P 500 directly from Standard \& Poor's. Data on the three-month T-bill, the default spread (between Moody's BAA and AAA corporate bond spreads), the term spread (between the ten-year T-bond and the three-month T-bill yields), and the stochastically detrended riskfree rate (the one-month T-bill rate minus its backward twelve-month moving averages) are taken from the public Web site of the Federal Reserve Bank of St. Louis. The CAY as defined in Lettau and Ludvigson (2001) is downloaded from Lettau and Ludvigson's Web site. ${ }^{19}$

Basic summary statistics for the monthly returns and predictor variables are given in Table 1. The mean excess return on the S\&P 500 over the sample equals $6.44 \%$ annually. The sample means for the implied and realized variances are 33.23 and 14.93 , respectively, corresponding to a variance risk premium of 18.30 (in percentages squared). The numbers for the traditional forecasting variables are all directly in line with those reported in previous studies. In particular, all of the variables are highly persistent with first-order autocorrelations ranging from 0.94 to 0.99 . In contrast, the serial correlation in the implied and

19 We define a monthly CAY series from the most recent quarterly observation. 
realized variances equal 0.79 and 0.70 , respectively, and the first-order autocorrelation for their difference only equals 0.49 . As such, this alleviates one of the common concerns related to the use of highly persistent predictor variables and the possibility of spurious or unbalanced regressions. ${ }^{20}$ Anticipating some of the results discussed next, the traditional predictor variables all correlate fairly weakly with the contemporaneous monthly excess returns, while the sample correlations between the monthly returns and the different variance measures are much higher (in an absolute sense), ranging from -0.34 to -0.23 .

\section{Forecasting Stock Market Returns}

All of our forecasts are based on simple linear regressions of the S\&P 500 excess returns on different sets of lagged predictor variables. We always rely on monthly observations. All of the reported $t$-statistics are based on heteroskedasticity and serial correlation consistent standard errors that explicitly take account of the overlap in the regressions following Hodrick (1992). ${ }^{21} \mathrm{We}$ focus our discussion on the estimated slope coefficients and their statistical significance as determined by the robust $t$-statistics. We also report the forecasts' accuracy of the regressions as measured by the corresponding adjusted $R^{2}$ s. However, as previously noted, for the more traditional highly persistent predictor variables, the $R^{2} \mathrm{~s}$ for the overlapping multi-period return regressions need to be interpreted with great caution. ${ }^{22}$

\subsection{Main empirical findings}

We begin by reporting in Table 2 the results for our empirical equivalent to the key return regression defined in Equation (17). The degree of predictability starts out fairly low at the monthly horizon with an $R^{2}$ of just above $1 \%$. The robust $t$-statistic for testing the estimated slope coefficient associated with the variance difference $I V-R V$ greater than zero still exceeds the one-sided $5 \%$ significance level. The quarterly return regression results in a much more impressive $t$-statistic of 2.86 and a corresponding $R^{2}$ of $6.82 \%$. The $t$-statistic remains significant at the six-month horizon, but the numerical values and significance then gradually taper off for longer return horizons.

20 Inference issues related to the use of highly persistent predictor variables have been studied extensively in the literature (see, for example, Stambaugh 1999; Ferson, Sarkissian, and Simin 2003; Lewellen 2004; Campbell and Yogo 2006 and references therein). Some authors have gone as far as to attribute the apparent predictability to the use of strongly serially correlated predictor variables (for example, Boudoukh, Richardson, and Whitelaw 2008; Goyal and Welch 2003, 2008).

21 Ang and Bekaert (2007) have forcefully shown that in the context of predictive regressions with overlapping observations, the standard errors obtained by summing the regressors in the past, as advocated by Hodrick (1992), are generally more reliable than the more traditional standard errors based on the summation of the residuals into the future as in, for example, Newey and West (1987).

22 Boudoukh, Richardson, and Whitelaw (2008) have recently shown that even in the absence of any increase in the true predictability, the values of the $R^{2} \mathrm{~s}$ with highly persistent predictor variables and overlapping returns will by construction increase roughly proportional with the return horizon and the length of the overlap (see also Kirby 1997). 
Table 2

Variance premium return regressions

\begin{tabular}{lcccccccc} 
Monthly return horizon & 1 & 3 & 6 & 9 & 12 & 15 & 18 & 24 \\
\hline Constant & -0.55 & -2.08 & 1.12 & 3.63 & 4.62 & 4.84 & 5.61 & 6.48 \\
& $(-0.13)$ & $(-0.56)$ & $(0.33)$ & $(1.15)$ & $(1.50)$ & $(1.59)$ & $(1.81)$ & $(2.07)$ \\
$I V_{t}-R V_{t}$ & 0.39 & 0.47 & 0.30 & 0.17 & 0.12 & 0.11 & 0.06 & 0.01 \\
& $(1.76)$ & $(2.86)$ & $(2.15)$ & $(1.36)$ & $(1.00)$ & $(0.94)$ & $(0.56)$ & $(0.11)$ \\
Adj. $R^{2}(\%)$ & 1.07 & 6.82 & 5.42 & 2.30 & 1.23 & 1.00 & 0.05 & -0.50 \\
\hline
\end{tabular}

The sample period extends from January 1990 to December 2007. All of the regressions are based on monthly observations. Robust $t$-statistics accounting for the overlap following Hodrick (1992) are reported in parentheses. All variable definitions are identical to Table 1.
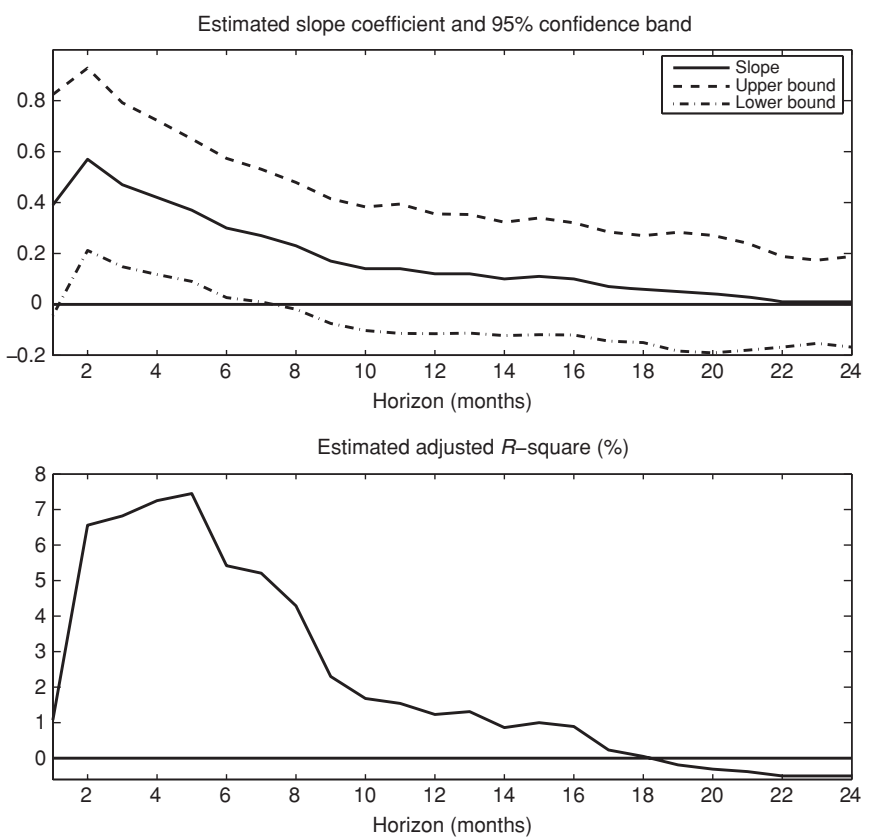

Figure 3

Estimated slopes and $R^{2} \mathbf{s}$

The figure shows the estimated slope coefficients and pointwise $95 \%$ confidence intervals along with the corresponding $R^{2}$ s from the regressions of the scaled $h$-period S\&P 500 returns on the variance difference. All of the regressions are based on monthly observations from January 1990 to December 2007.

Taken as a whole, the results in Table 2 reveal a clear pattern in the degree of predictability afforded by the variance risk premium with the largest $t$-statistic and maximum $R^{2}$ occurring at the quarterly horizon. These findings are directly in line with the qualitative implications from the theoretical model developed in Section 2, in which the variance risk premium effectively isolates the systematic risk factor associated with time-varying volatility of consumption growth volatility. More specifically, comparing the empirical estimates for all of the monthly horizons ranging from one month $(h=1)$ to two years $(h=24)$ reported in Figure 3 to the theoretical population counterparts for the 
four benchmark models depicted in Figure 1, the similarities in the general shapes of the estimated and implied slope coefficients and $R^{2} \mathrm{~s}$ as a function of the return horizon are quite striking. Of course, the values of the $R^{2} \mathrm{~s}$ at the intermediate three-to six-month horizon for the actual return regressions are slightly larger than the $R^{2}$ s for any of the calibrated models, suggesting that additional systematic risk factors, temporal variation in the degree of risk aversion, and/or the influence of period-specific idiosyncratic events are needed to fully explain the empirical results.

To better appreciate the findings in a wider empirical context, Tables 3-5 report the results from comparable monthly, quarterly, and annual return regressions, respectively, involving the more traditional predictor variables in Table $1 .^{23}$ Not surprisingly, the degree of predictability at the monthly horizon is systematically very low, although the individual regressions for both the $\mathrm{P} / \mathrm{E}$ ratio and CAY do result in $t$-statistics slightly above two (numerically). ${ }^{24}$ Combining the variance difference with the $\mathrm{P} / \mathrm{E}$ ratio results in a monthly $R^{2}$ of $3.77 \%$, in excess of the sum of the two $R^{2}$ s from the individual regressions. Both of the coefficients also remain statistically significant in the joint regression. Adding the term spread (TMSP) and the relative risk-free rate (RREL) to the multiple regression actually reduces the (adjusted) $R^{2}$, but the variance premium remains statistically significant.

The quarterly regressions reported in Table 4 further underscore the significance of the result in Table 2. None of the $t$-statistics for any of the other predictor variables come close to the aforementioned $t$-statistic for the variance premium (2.86), and with the possible exception of P/E $(-1.97)$ and CAY (1.78), all are insignificant at conventional levels. Of course, the $R^{2} \mathrm{~s}$ for some of the other predictor variables, most notably the P/E and P/D ratios and CAY, are fairly close to the $R^{2}$ for the variance premium. However, whereas the monthly variance premium exhibits relatively weak serial correlation, all of these other predictor variables are close to unit root-type processes, which as previously noted renders the $R^{2}$ s based on overlapping regressions difficult to interpret.

Turning to the multiple regressions reported in the right panel of Table 4, we find that combining the variance premium with the $\mathrm{P} / \mathrm{E}$ ratio results in even more impressive $t$-statistics of 3.43 and -2.42 , respectively. Intuitively, the variance risk premium and the $\mathrm{P} / \mathrm{E}$ ratio may jointly capture important

${ }^{23}$ For comparability with the other slope coefficients, the P/E, P/D, and DFSP variables have been scaled by a factor of 12. Many other predictor variables have, of course, been proposed in the literature. While it is literally impossible to investigate all of these suggestions, we also experimented with the bond factor of Cochrane and Piazzesi (2005), but found that it offered little predictability over the 1990-2007 sample period. Similarly, return regressions based on the corporate payout ratio (D/E) resulted in a negative adjusted $R^{2}$ over the present sample.

24 By estimating the cointegrating relationship in-sample, the traditional CAY variable suffers from a "look-ahead" bias. Brennan and Xia (2005) argue that this "explains" most of the predictability afforded by CAY. Also, on implementing the aforementioned adjustment in Stambaugh $(1986,1999)$ to take account of the finite-sample bias in the estimated coefficients due to the serial correlation in the regressors, the adjustment term for $I V_{t}-R V_{t}$ equals 0.02 , compared to 0.52 and 0.51 for $\mathrm{P} / \mathrm{E}$ and $\mathrm{CAY}$, respectively. These latter large adjustments are directly in line with the numbers reported in the extant literature. 
Table 3

Monthly return regressions

\begin{tabular}{|c|c|c|c|c|c|c|c|c|c|c|c|c|c|c|}
\hline & & & & & Simple & & & & & & & Multiple & & \\
\hline Constant & $\begin{array}{c}-0.55 \\
(-0.13)\end{array}$ & $\begin{array}{c}-0.19 \\
(-0.04)\end{array}$ & $\begin{array}{c}4.88 \\
(1.20)\end{array}$ & $\begin{array}{c}92.72 \\
(2.22)\end{array}$ & $\begin{array}{c}75.51 \\
(1.87)\end{array}$ & $\begin{array}{l}14.23 \\
(0.91)\end{array}$ & $\begin{array}{c}7.73 \\
(1.32)\end{array}$ & $\begin{array}{c}6.67 \\
(2.12)\end{array}$ & $\begin{array}{c}5.45 \\
(1.53)\end{array}$ & $\begin{array}{c}101.13 \\
(2.42)\end{array}$ & $\begin{array}{c}-2.52 \\
(-0.55)\end{array}$ & $\begin{array}{c}78.02 \\
(1.49)\end{array}$ & $\begin{array}{l}91.20 \\
(1.74)\end{array}$ & $\begin{array}{r}101.86 \\
(2.28)\end{array}$ \\
\hline$I V_{t}-R V_{t}$ & $\begin{array}{c}0.39 \\
(1.76)\end{array}$ & & & & & & & & & $\begin{array}{c}0.49 \\
(2.16)\end{array}$ & $\begin{array}{c}0.42 \\
(1.87)\end{array}$ & & $\begin{array}{c}0.50 \\
(2.10)\end{array}$ & $\begin{array}{c}0.57 \\
(2.34)\end{array}$ \\
\hline$I V_{t}$ & & $\begin{array}{c}0.20 \\
(1.30)\end{array}$ & & & & & & & & & & & & \\
\hline$R V_{t}$ & & & $\begin{array}{c}0.11 \\
(0.41)\end{array}$ & & & & & & & & & & & \\
\hline $\log \left(P_{t} / E_{t}\right)$ & & & & $\begin{array}{l}-2.30 \\
(-2.02)\end{array}$ & & & & & & $\begin{array}{l}-2.76 \\
(-2.40)\end{array}$ & & $\begin{array}{l}-1.90 \\
(-1.36)\end{array}$ & $\begin{array}{c}-2.49 \\
(-1.76)\end{array}$ & $\begin{array}{c}-2.93 \\
(-2.31)\end{array}$ \\
\hline $\log \left(P_{t} / D_{t}\right)$ & & & & & $\begin{array}{l}-1.47 \\
(-1.68)\end{array}$ & & & & & & & & & \\
\hline$D F S P_{t}$ & & & & & & $\begin{array}{c}-0.77 \\
(-0.50)\end{array}$ & & & & & & & & \\
\hline$T M S P_{t}$ & & & & & & & $\begin{array}{l}-0.72 \\
(-0.28)\end{array}$ & & & & & & & $\begin{array}{c}2.87 \\
(0.96)\end{array}$ \\
\hline$R R E L_{t}$ & & & & & & & & $\begin{array}{c}1.63 \\
(0.43)\end{array}$ & & & & & & $\begin{array}{c}3.29 \\
(0.76)\end{array}$ \\
\hline$C A Y_{t}$ & & & & & & & & & $\begin{array}{c}3.71 \\
(2.04)\end{array}$ & & $\begin{array}{c}3.94 \\
(2.20)\end{array}$ & $\begin{array}{c}1.78 \\
(0.87)\end{array}$ & $\begin{array}{c}1.46 \\
(0.72)\end{array}$ & \\
\hline Adj. $R^{2}(\%)$ & 1.07 & 0.57 & -0.34 & 1.80 & 1.11 & -0.31 & -0.43 & -0.40 & 1.44 & 3.77 & 2.78 & 1.89 & 3.86 & 3.34 \\
\hline
\end{tabular}

The sample period extends from January 1990 to December 2007. Robust $t$-statistics following Hodrick (1992) are reported in parentheses. All variable definitions are identical to Table 1, except for $\mathrm{P} / \mathrm{E}, \mathrm{P} / \mathrm{D}$, and DFSP, which have been scaled by a factor of 12 . 
Table 4

Quarterly return regressions

Simple Multiple

\begin{tabular}{|c|c|c|c|c|c|c|c|c|c|c|c|c|c|c|}
\hline Constant & $\begin{array}{c}-2.08 \\
(-0.56)\end{array}$ & $\begin{array}{c}0.24 \\
(0.06)\end{array}$ & $\begin{array}{c}6.60 \\
(1.60)\end{array}$ & $\begin{array}{l}92.41 \\
(2.17)\end{array}$ & $\begin{array}{l}73.35 \\
(1.81)\end{array}$ & $\begin{array}{c}20.63 \\
(1.32)\end{array}$ & $\begin{array}{c}7.39 \\
(1.24)\end{array}$ & $\begin{array}{c}6.92 \\
(2.18)\end{array}$ & $\begin{array}{c}5.53 \\
(1.54)\end{array}$ & $\begin{array}{r}101.89 \\
(2.40)\end{array}$ & $\begin{array}{c}-4.12 \\
(-1.00)\end{array}$ & $\begin{array}{c}85.93 \\
(1.67)\end{array}$ & $\begin{array}{r}100.06 \\
(1.93)\end{array}$ & $\begin{array}{l}98.21 \\
(2.18)\end{array}$ \\
\hline$I V_{t}-R V_{t}$ & $\begin{array}{c}0.47 \\
(2.86)\end{array}$ & & & & & & & & & $\begin{array}{c}0.58 \\
(3.43)\end{array}$ & $\begin{array}{c}0.51 \\
(3.02)\end{array}$ & & $\begin{array}{c}0.59 \\
(3.38)\end{array}$ & $\begin{array}{c}0.70 \\
(4.01)\end{array}$ \\
\hline$I V_{t}$ & & $\begin{array}{c}0.19 \\
(1.41)\end{array}$ & & & & & & & & & & & & \\
\hline$R V_{t}$ & & & $\begin{array}{c}0.00 \\
(0.00)\end{array}$ & & & & & & & & & & & \\
\hline $\log \left(P_{t} / E_{t}\right)$ & & & & $\begin{array}{l}-2.28 \\
(-1.97)\end{array}$ & & & & & & $\begin{array}{c}-2.82 \\
(-2.42)\end{array}$ & & $\begin{array}{l}-2.11 \\
(-1.54)\end{array}$ & $\begin{array}{l}-2.77 \\
(-1.98)\end{array}$ & $\begin{array}{l}-2.95 \\
(-2.33)\end{array}$ \\
\hline $\log \left(P_{t} / D_{t}\right)$ & & & & & $\begin{array}{c}-1.42 \\
(-1.62)\end{array}$ & & & & & & & & & \\
\hline$D F S P_{t}$ & & & & & & $\begin{array}{c}-1.39 \\
(-0.90)\end{array}$ & & & & & & & & \\
\hline$T M S P_{t}$ & & & & & & & $\begin{array}{c}-0.46 \\
(-0.17)\end{array}$ & & & & & & & $\begin{array}{c}4.08 \\
(1.42)\end{array}$ \\
\hline$R R E L_{t}$ & & & & & & & & $\begin{array}{c}3.27 \\
(0.88)\end{array}$ & & & & & & $\begin{array}{c}6.39 \\
(1.56)\end{array}$ \\
\hline$C A Y_{t}$ & & & & & & & & & $\begin{array}{c}3.23 \\
(1.78)\end{array}$ & & $\begin{array}{c}3.52 \\
(1.99)\end{array}$ & $\begin{array}{c}1.08 \\
(0.53)\end{array}$ & $\begin{array}{c}0.74 \\
(0.37)\end{array}$ & \\
\hline Adj. $R^{2}(\%)$ & 6.82 & 2.49 & -0.47 & 6.55 & 4.19 & 1.18 & -0.43 & 0.43 & 4.13 & 16.76 & 11.87 & 7.21 & 17.42 & 19.74 \\
\hline
\end{tabular}

The sample period extends from January 1990 to December 2007. All of the regressions are based on overlapping monthly observations. Robust $t$-statistics accounting for the overlap following Hodrick (1992) are reported in parentheses. All variable definitions are identical to Tables 1 and 3. 
Table 5

Annual return regressions

\begin{tabular}{|c|c|c|c|c|c|c|c|c|c|c|c|c|c|c|}
\hline & & & & & Simple & & & & & & & Multiple & & \\
\hline Constant & $\begin{array}{c}4.62 \\
(1.50)\end{array}$ & $\begin{array}{c}7.62 \\
(2.44)\end{array}$ & $\begin{array}{c}9.49 \\
(3.20)\end{array}$ & $\begin{array}{l}78.47 \\
(2.05)\end{array}$ & $\begin{array}{l}79.83 \\
(2.17)\end{array}$ & $\begin{array}{l}15.59 \\
(1.13)\end{array}$ & $\begin{array}{c}5.37 \\
(0.90)\end{array}$ & $\begin{array}{c}7.29 \\
(2.33)\end{array}$ & $\begin{array}{c}5.42 \\
(1.47)\end{array}$ & $\begin{array}{l}81.00 \\
(2.15)\end{array}$ & $\begin{array}{c}1.91 \\
(0.53)\end{array}$ & $\begin{array}{l}52.85 \\
(1.03)\end{array}$ & $\begin{array}{l}55.11 \\
(1.08)\end{array}$ & $\begin{array}{c}74.04 \\
(1.88)\end{array}$ \\
\hline$I V_{t}-R V_{t}$ & $\begin{array}{c}0.12 \\
(1.00)\end{array}$ & & & & & & & & & $\begin{array}{c}0.19 \\
(1.68)\end{array}$ & $\begin{array}{c}0.18 \\
(1.51)\end{array}$ & & $\begin{array}{c}0.20 \\
(1.74)\end{array}$ & $\begin{array}{c}0.33 \\
(2.96)\end{array}$ \\
\hline$I V_{t}$ & & $\begin{array}{l}-0.02 \\
(-0.21)\end{array}$ & & & & & & & & & & & & \\
\hline$R V_{t}$ & & & $\begin{array}{c}-0.17 \\
(-1.20)\end{array}$ & & & & & & & & & & & \\
\hline $\log \left(P_{t} / E_{t}\right)$ & & & & $\begin{array}{c}-1.90 \\
(-1.80)\end{array}$ & & & & & & $\begin{array}{l}-2.06 \\
(-2.00)\end{array}$ & & $\begin{array}{c}-1.24 \\
(-0.91)\end{array}$ & $\begin{array}{l}-1.40 \\
(-1.03)\end{array}$ & $\begin{array}{l}-2.14 \\
(-1.92)\end{array}$ \\
\hline $\log \left(P_{t} / D_{t}\right)$ & & & & & $\begin{array}{l}-1.55 \\
(-1.92)\end{array}$ & & & & & & & & & \\
\hline$D_{F S P}$ & & & & & & $\begin{array}{c}-0.87 \\
(-0.64)\end{array}$ & & & & & & & & \\
\hline$T M S P_{t}$ & & & & & & & $\begin{array}{c}0.88 \\
(0.35)\end{array}$ & & & & & & & $\begin{array}{c}4.53 \\
(1.69)\end{array}$ \\
\hline$R R E L_{t}$ & & & & & & & & $\begin{array}{c}4.09 \\
(1.11)\end{array}$ & & & & & & $\begin{array}{c}6.29 \\
(1.75)\end{array}$ \\
\hline$C A Y_{t}$ & & & & & & & & & $\begin{array}{c}3.48 \\
(1.99)\end{array}$ & & $\begin{array}{c}3.62 \\
(2.12)\end{array}$ & $\begin{array}{c}2.13 \\
(0.99)\end{array}$ & $\begin{array}{c}2.12 \\
(0.99)\end{array}$ & \\
\hline Adj. $R^{2}(\%)$ & 1.23 & -0.37 & 2.89 & 16.34 & 19.53 & 1.79 & 0.01 & 4.54 & 18.15 & 20.12 & 21.18 & 21.46 & 25.52 & 32.58 \\
\hline
\end{tabular}

The sample period extends from January 1990 to December 2007. All of the regressions are based on overlapping monthly observations. Robust $t$-statistics accounting for the overlap following Hodrick (1992) are reported in parentheses. All variable definitions are identical to Tables 1 and 3. 
short- and long-run risks embedded in the market returns. This would also be consistent with the qualitative implications from a more elaborate equilibrium model combining the model in Section 2 with the long-run risk model of Bansal and Yaron (2004), allowing for time-varying volatility and volatilityof-volatility as well as predictability in the mean of consumption growth. A similar empirical pattern, albeit to a lesser extent, obtains when including the CAY variable along with the variance premium, resulting in $t$-statistics of 3.02 and 1.99, respectively. On the other hand, combining the P/E ratio and CAY in the same quarterly return regressions results in insignificant $t$-statistics for both. Even though the term spread and the relative short rate are insignificant by themselves, both variables contribute marginally to a joint predictive regression with the variance premium and the $\mathrm{P} / \mathrm{E}$ ratio, resulting in the highest overall adjusted $R^{2}$ in the table. Lastly, it is worth noting that regardless of the other variables included in the forecast regressions, the estimated coefficients for the variance risk premium remain quite stable and statistically significant at the 0.001 level or better.

Many of the empirical studies cited above have, of course, argued that the degree of predictability afforded by the different valuation ratios and predictor variables included in Table 1 tend to be the strongest over longer multi-year horizons. Our limited post-1990 sample prevents us from effectively studying issues having to do with longer return horizons spanning multiple years. However, we do report in Table 5 the regression results for annual returns based on monthly overlapping observations, but again caution that with such a short calendar time span and large overlap, the estimation results, and especially the $R^{2} \mathrm{~s}$, must be carefully interpreted. Indeed, despite the large $R^{2} \mathrm{~s}$, the $t$-statistics for P/E, P/D, and CAY are all just barely significant. As before, including the variance premium with either of these other variables results in larger (in an absolute sense) $t$-statistics for both. In parallel to Tables 3 and 4 , the overall largest $t$-statistic (2.96) is again associated with the variance premium in the multiple regression reported in the last column in the table.

The simple regressions involving $R V$ or $I V$ reported in Tables 3-5 always result in insignificant $t$-statistics and low $R^{2} \mathrm{~s}$. This is, of course, to be expected from the extant risk-return literature, which has largely searched in vain for such a tradeoff relationship. To further explore this issue and the interplay between the two volatility measures, we report in Table 6 the results obtained by including $R V$ and $V R P=I V-R V$ in the same return regressions. Looking at the quarterly return horizon in the middle part of the table, it is noteworthy that while $V R P$ is highly significant, $R V$ remains insignificant in the joint regression. As such, this implicitly attributes the same numerical but opposite signed effects to $I V$ and $R V$. Following the discussion in Section 2, it appears that the variance difference $V R P$ effectively isolates the factor that drives the volatility risk premium, thereby allowing for the estimation of a meaningful and significant risk-return tradeoff relationship. Meanwhile, previous studies in the risk-return literature (for example, Scruggs 1998; Guo and Whitelaw 2006) have argued 
Table 6

Risk-return tradeoff

\begin{tabular}{cccccccccc} 
& \multicolumn{3}{c}{ Monthly returns } & \multicolumn{3}{c}{ Quarterly returns } & \multicolumn{3}{c}{ Annual returns } \\
\hline Constant & -0.83 & 112.29 & 134.16 & -0.88 & 113.52 & 121.71 & 6.84 & 78.82 & 81.17 \\
& $(-0.18)$ & $(2.88)$ & $(2.85)$ & $(-0.21)$ & $(2.77)$ & $(2.71)$ & $(2.22)$ & $(2.28)$ & $(2.16)$ \\
$R V_{t}$ & 0.03 & 0.32 & 0.46 & -0.11 & 0.17 & 0.33 & -0.22 & -0.03 & 0.10 \\
& $(0.10)$ & $(1.22)$ & $(1.58)$ & $(-0.41)$ & $(0.65)$ & $(1.11)$ & $(-1.25)$ & $(-0.23)$ & $(0.75)$ \\
$I V_{t}-R V_{t}$ & 0.38 & 0.45 & 0.54 & 0.50 & 0.56 & 0.69 & 0.17 & 0.20 & 0.33 \\
& $(1.68)$ & $(2.02)$ & $(2.43)$ & $(2.91)$ & $(3.42)$ & $(4.22)$ & $(1.43)$ & $(1.73)$ & $(2.94)$ \\
$\log \left(P_{t} / E_{t}\right)$ & & -3.43 & -4.06 & & -3.18 & -3.76 & & -1.99 & -2.39 \\
& & $(-2.91)$ & $(-2.93)$ & & $(-2.80)$ & $(-2.87)$ & & $(-2.13)$ & $(-2.23)$ \\
$T M S P_{t}$ & & & 4.95 & & & 5.52 & & & 4.97 \\
& & & $(1.48)$ & & & $(1.68)$ & & & $(1.82)$ \\
$R R E L_{t}$ & & & 5.09 & & & 7.55 & & & 6.62 \\
& & & $(1.17)$ & & & $(1.82)$ & & & $(1.87)$ \\
Adj. $R^{2}(\%)$ & 0.61 & 4.17 & 4.45 & 6.78 & 17.11 & 21.81 & 5.80 & 19.80 & 33.00
\end{tabular}

The sample period extends from January 1990 to December 2007. All of the regressions are run at a monthly frequency. Robust $t$-statistics accounting for the overlap following Hodrick (1992) are reported in parentheses. All variable definitions are identical to Tables 1 and 3 .

that additional control factors, including interest rates, are needed in order to reliably estimate the relationship between expected return and volatility. ${ }^{25}$ To investigate this, we include the $\mathrm{P} / \mathrm{E}$ ratio, the term spread, and the short rate in the return regressions. This only reinforces the superior predictability afforded by the variance premium. Whereas many of the $t$-statistics for the variance premium (all at the quarterly horizon) are highly significant, none of the $t$-statistics associated with $R V$ and the more traditional risk-return tradeoff estimated in the literature are significant.

\subsection{Other variation measures}

The regression results discussed above were directly motivated by the stylized equilibrium model in Section 2, in which the dynamics were cast in variance form, and in which the different variation measures were approximated empirically by their "model-free" counterparts. We next discuss a series of additional return regressions and sensitivity checks based on other variation measures and volatility transforms designed to address the robustness and validity of our findings in a wider sense. To conserve space, we will focus our summary discussion on the quarterly return horizon that produced the most significant results. Also, we do not include any additional tables, but more detailed tabular information related to these results is available upon request.

3.2.1 "Old" variance measures. The "model-free" implied and realized variances underlying our empirical results are both relatively new. As a first robustness check, we replace the "model-free" variance measures with the standard at-the-money Black-Scholes implied variance $I V^{*}$, and the realized

25 With higher interest rates generally associated with more turbulent financial markets, this may also be seen as proxying for the $q_{t}$ process in the stylized equilibrium model. 
variance based on low-frequency daily returns $R V^{*}$. Interestingly, the regressions based on these "old" variance measures generally do not give rise to the same strong conclusions. The variance risk premium defined by the difference between the Black-Scholes implied variance and the daily return based realized variance still dominates each of the variance measures in isolation with $t$-statistics of 1.72 versus 0.97 and 0.31 , respectively. However, the $R^{2}$ for the "model-free" variance premium in Table 4 (6.82\%) is much larger than the $2.16 \%$ obtained with the difference between the "old" variance measures. Replacing the realized variance based on daily data with the corresponding high-frequency-based measure results in a marginally significant $t$-statistic of 1.85 and increases the $R^{2}$ to $3.30 \%$. Similarly, replacing the Black-Scholes implied variance with the "model-free" implied variance results in a $t$-statistic of 2.34 and increases the $R^{2}$ to $4.45 \% .^{26}$

All in all, these results clearly show that our use of the new "model-free" variance measures is crucial in effectively uncovering the variance risk premium. Estimation of the same predictive regressions based on the traditional Black-Scholes implied variances and/or realized variances constructed from lower frequency daily data does not give rise to nearly as significant results.

3.2.2 Volatility risk premia. The regressions discussed so far have all been cast in variance form. ${ }^{27}$ This, of course, directly mirrors the expressions for the variance premia and predictability regressions derived within the context of the theoretical model in Section 2. However, the volatility, or other nonlinear monotone transforms of the variance, is often used as an alternative and empirically more robust measure of risk (for example, Merton 1980). Replacing the "model-free" variance measures with their volatility or standard deviation counterparts yields a $t$-statistic of 2.75 and an $R^{2}$ of $6.51 \%$ for the volatility difference $\sqrt{I V}-\sqrt{R V}$, compared to 2.86 and $6.82 \%$ for the variance difference $I V-R V$. Again, including $\sqrt{I V}$ and $\sqrt{R V}$ individually results in insignificant $t$-statistics of 1.01 and -0.12 , respectively. The results for the multiple regressions obtained by including the $\mathrm{P} / \mathrm{E}$ ratio, CAY, and the term structure variables together with the volatility difference are comparable to the ones for the variance premium, but all of the $t$-statistics and $R^{2} \mathrm{~s}$ fall short of those reported in Table 4.

3.2.3 Expected variation premium. The empirical variance risk premium defined in Equation (22) is based on the difference between the market's (risk neutral) expected variation and the current realized variation. Both of these measures and in turn the premium are directly observable at time $t$ in a completely

26 This indirectly suggests that much of the useful information about the temporal variation in the risk-neutralized variance resides in options away from the money.

27 This corresponds to the common use of variance-denominated contracts in the over-the-counter swap market (see, for example, Demeterfi et al. 1999; Mixon 2007). 
"model-free" fashion. The resulting regressions with VRP on the right-hand side also directly mirror the population regressions analyzed within the stylized equilibrium model in Section 2. More generally, however, our empirical findings that higher (lower) values of the variance premium are associated with higher (lower) future returns may, in part, be attributed to the effect that when the market anticipates high (low) volatility going forward, there is a discount (premium) built into prices, resulting in high (low) future returns. To more clearly separate this effect from temporal variation in the volatility risk premium per se, it is useful to consider a regression of the returns on an estimate of the previously defined forward looking, ${ }^{28}$ or expected, variance premium, $E V R P_{t} \equiv I V_{t}-E_{t}\left(R V_{t+1}\right)$.

In contrast to all of the other predictor variables and "model-free" empirical measures considered so far, this necessitates an explicit forecasting model for $R V_{t}$. Numerous parametric and nonparametric volatility forecasting procedures have been proposed in the literature (see, for example, Andersen et al. 2006). We here rely on the simple-to-implement, yet empirically highly accurate, reduced form HAR-RV model advocated by Corsi (2004) and Andersen, Bollerslev, and Diebold (2007), among others, in which the forecast for the one-month-ahead volatility is a linear function of the current daily, weekly, and monthly realized volatilities. Regressing the quarterly overlapping returns on a constant and this expected variance premium results in a $t$-statistic of 2.27 and an $R^{2}$ of $4.27 .{ }^{29}$ Although this $t$-statistic for EVRP is somewhat lower than the one for VRP (2.86), it is still higher than the $t$-statistics for any of the other predictor variables in Table 4. Of course, given the high degree of volatility persistence inherent in the S\&P 500 returns, it is hardly surprising that the expected variance difference and the directly observable variance difference perform fairly similarly from a forecasting perspective. ${ }^{30}$

\section{Conclusion}

We provide empirical evidence that stock market returns are predictable by the difference between "model-free" implied and realized variances or the variance risk premium. The results appear remarkably robust across different specifications and/or the inclusion of alternative predictor variables. The degree of predictability is the largest at intermediate quarterly horizons, but the premium still helps explain the observed return variation at shorter monthly and longer annual horizons. Our empirical findings are broadly consistent with the implications from a simple representative agent economy with recursive preferences

28 Related to this, Ang et al. (2009) rely on forward looking volatility estimates constructed by instrumental variables procedures in their analysis of cross-sectional pricing of idiosyncratic volatility.

29 Since our estimation of the HAR-RV model for $R V_{t}$ is based on the full sample, the results are subject to a standard "look-ahead" bias and additional parameter estimation error uncertainty.

30 The sample correlation between EVRP and VRP equals 0.85 , which far exceeds that for any other pair of predictor variables in Table 1. 
that explicitly incorporates the equilibrium effects of economic uncertainty and time-varying volatility-of-volatility, although the magnitudes of the estimated effects appear too large to be fully explained by the new stylized theoretical model.

The wedge between the "model-free" risk-neutral expected and actual variance underlying our empirical results may alternatively be seen as a proxy for the aggregate degree of risk aversion in the market. ${ }^{31}$ Although it might be difficult to contemplate systematic changes in the level of risk aversion at the frequencies emphasized in our empirical work, time-varying volatility risk and time-varying risk aversion likely both play an important role in explaining temporal variation in expected returns (for example, Bekaert, Engstrom, and Grenadier 2005; Bekaert, Engstrom, and Xing 2008). Recent work directly motivated by the empirical results first reported here based on more elaborate equilibrium models (Drechsler and Yaron 2008) and cross-sectional pricing relations (Nyberg and Wilhelmsson 2007) should prove an important next step in sorting out these issues and further clarify the economic mechanisms behind the predictability afforded by the variance risk premium.

\section{References}

Aït-Sahalia, Y., and A. W. Lo. 2000. Nonparametric Risk Management and Implied Risk Aversion. Journal of Econometrics 94:9-51.

Andersen, T. G., T. Bollerslev, P. F. Christoffersen, and F. X. Diebold. 2006. Volatility and Correlation Forecasting. In G. Elliott, C. W. J. Granger, and A. Timmermann (eds.), Handbook of Economic Forecasting, chap. 15, pp. 777-878. Amsterdam: Elsevier.

Andersen, T. G., T. Bollerslev, and F. X. Diebold. 2007. Roughing It Up: Including Jump Components in the Measurement, Modeling, and Forecasting of Return Volatility. Review of Economics and Statistics 89:701-20.

Andersen, T. G., T. Bollerslev, F. X. Diebold, and H. Ebens. 2001a. The Distribution of Realized Stock Return Volatility. Journal of Financial Economics 61:43-76.

Andersen, T. G., T. Bollerslev, F. X. Diebold, and P. Labys. 2000. Great Realizations. Risk 13:105-8.

Andersen, T. G., T. Bollerslev, F. X. Diebold, and P. Labys. 2001b. The Distribution of Realized Exchange Rate Volatility. Journal of the American Statistical Association 96:42-55.

Ang, A., and G. Bekaert. 2007. Stock Return Predictability: Is it There? Review of Financial Studies 20:651-707.

Ang, A., R. Hodrick, Y. Xing, and X. Zhang. 2006. The Cross-Section of Volatility and Expected Returns. Journal of Finance 61:259-99.

Ang, A., R. Hodrick, Y. Xing, and X. Zhang. 2009. High Idiosyncratic Volatility and Low Returns: International and Further U.S. Evidence. Journal of Financial Economics 91:1-23.

Ang, A., and J. Liu. 2007. Risk, Return, and Dividends. Journal of Financial Economics 85:138.

Bakshi, G., and D. Madan. 2006. A Theory of Volatility Spread. Management Science 52:1945-56.

31 More complicated model-specific measures of risk aversion based on the information in options prices have previously been explored empirically by a number of studies (see, for example, Ait-Sahalia and Lo 2000; Rosenberg and Engle 2002; Brandt and Wang 2003; Gordon and St-Amour 2004; Wu 2005; Garcia et al. 2006; Ziegler 2007). 
Bansal, R., V. Khatchatrian, and A. Yaron. 2005. Interpretable Asset Markets? European Economic Review 49:531-60.

Bansal, R., and A. Yaron. 2004. Risks for the Long Run: A Potential Resolution of Asset Pricing Puzzles. Journal of Finance 59:1481-509.

Barndorff-Nielsen, O., and N. Shephard. 2002. Econometric Analysis of Realized Volatility and Its Use in Estimating Stochastic Volatility Models. Journal of Royal Statistical Society, B 64:253-80.

Barndorff-Nielsen, O. E., P. R. Hansen, A. Lunde, and N. Shephard. 2008. Designing Realised Kernels to Measure the Ex-post Variation of Equity Prices in the Presence of Noise. Econometrica 76:1481-1536.

Beckers, S., and T. Bouten. 2005. Implied Volatility and Market Timing. Finance Letters 3:12-16.

Bekaert, G., E. Engstrom, and S. R. Grenadier. 2005. Stock and Bond Returns with Moody Investors. Working Paper, Columbia University.

Bekaert, G., E. Engstrom, and Y. Xing. 2008. Risk, Uncertainty, and Asset Prices. Journal of Financial Economics.

Bekaert, G., and J. Liu. 2004. Conditioning Information and Variance Bounds on Pricing Kernels. Review of Financial Studies 17:339-78.

Bollerslev, T., M. Gibson, and H. Zhou. 2006. Dynamic Estimation of Volatility Risk Premia and Investor Risk Aversion from Option-Implied and Realized Volatilities. Working Paper, Federal Reserve Board.

Bondarenko, O. 2004. Market Price of Variance Risk and Performance of Hedge Funds. Working Paper, University of Illinois.

Boudoukh, J., M. Richardson, and R. F. Whitelaw. 2008. The Myth of Long-Horizon Predictability. Review of Financial Studies 21:1577-1605.

Brandt, M. W., and K. Q. Wang. 2003. Time-Varying Risk Aversion and Expected Inflation. Journal of Monetary Economics 50:1457-98.

Brennan, M. J., and Y. Xia. 2005. TAY's as Good as CAY. Finance Research Letters 2:1-14.

Britten-Jones, M., and A. Neuberger. 2000. Option Prices, Implied Price Processes, and Stochastic Volatility. Journal of Finance 55:839-66.

Campbell, J. Y., and R. J. Shiller. 1988. The Dividend-Price Ratio and Expectations of Future Dividends and Discount Factors. Review of Financial Studies 1(3):195-228.

Campbell, J. Y., and M. Yogo. 2006. Efficient Tests of Stock Return Predictability. Journal of Financial Economics $81: 27-60$.

Carr, P., and D. Madan. 1998. Towards a Theory of Volatility Trading. In R. Jarrow (ed.), Volatility: New Estimation Techniques for Pricing Derivatives, chap. 29, pp. 417-27. London: Risk Books.

Carr, P., and L. Wu. 2009. Variance Risk Premia. Review of Financial Studies 22.

Cochrane, J. H. 2008. The Dog That Did Not Bark: A Defense of Return Predictability. Review of Financial Studies 21:1533-75.

Cochrane, J. H., and M. Piazzesi. 2005. Bond Risk Premia. American Economic Review 95:138-60.

Corsi, F. 2004. A Simple Long Memory Model of Realized Volatility. Working Paper, University of Southern Switzerland.

Demeterfi, K., E. Derman, M. Kamal, and J. Zou. 1999. A Guide to Volatility and Variance Swaps. Journal of Derivatives 6:9-32.

Drechsler, I., and A. Yaron. 2008. What's Vol Got to Do with It. Working Paper, University of Pennsylvania.

Epstein, L. G., and S. E. Zin. 1991. Substitution, Risk Aversion, and the Temporal Behavior of Consumption and Asset Returns: An Empirical Analysis. Journal of Political Economy 99:263-86. 
Ferson, W. E., S. Sarkissian, and T. T. Simin. 2003. Spurious Regressions in Financial Economics? Journal of Finance 58:1393-414.

Garcia, R., M.-A. Lewis, S. Pastorello, and E. Renault. 2006. Estimation of Objective and Risk-Neutral Distributions Based on Moments of Integrated Volatility. Working Paper, CRDE, Université de Montréal.

Gordon, S., and P. St-Amour. 2004. Asset Returns and State-Dependent Risk Preferences. Journal of Business and Economic Statistics 22:241-52.

Goyal, A., and I. Welch. 2003. Predicting the Equity Premium with Dividend Ratios. Management Science 49:639-54.

Goyal, A., and I. Welch. 2008. A Comprehensive Look at the Empirical Performance of Equity Premium Prediction. Review of Financial Studies 21:1455-1508.

Guo, H., and R. F. Whitelaw. 2006. Uncovering the Risk-Return Relation in the Stock Market. Journal of Finance $61: 1433-63$.

Hansen, P. R., and A. Lunde. 2006. Realized Variance and Market Microstructure Noise. Journal of Business and Economic Statistics 24:127-61.

Heston, S. 1993. A Closed-Form Solution for Options with Stochastic Volatility with Applications to Bond and Currency Options. Review of Financial Studies 6:327-43.

Hodrick, R. J. 1992. Dividend Yields and Expected Stock Returns: Alternative Procedures for Inference and Measurement. Review of Financial Studies 5:357-86.

Hsieh, D. A. 1991. Chaos and Nonlinear Dynamics: Application to Financial Markets. Journal of Finance 46:1839-77.

Jiang, G., and Y. Tian. 2005. Model-Free Implied Volatility and Its Information Content. Review of Financial Studies 18:1305-42.

Jiang, G. J., and Y. S. Tian. 2007. Extracting Model-Free Volatility from Option Prices: An Examination of the VIX Index. Journal of Derivatives 14:1-26.

Kirby, C. 1997. Measuring the Predictable Variation in Stock and Bond Returns. Review of Financial Studies 10:579-630.

Kreps, D. M., and E. L. Porteus. 1978. Temporal Resolution of Uncertainty and Dynamic Choice Theory. Econometrica 46:185-200.

Lamont, O. 1998. Earnings and Expected Returns. Journal of Finance 53:1563-87.

Lettau, M., and S. Ludvigson. 2001. Consumption, Aggregate Wealth, and Expected Stock Returns. Journal of Finance 56:815-49.

Lettau, M., S. Ludvigson, and J. Wachter. 2008. The Declining Equity Premium: What Role Does Macroeconomic Risk Play? Review of Financial Studies 21:1653-87.

Lewellen, J. 2004. Predicting Returns with Financial Ratios. Journal of Financial Economics 74:209-35.

Meddahi, N. 2002. Theoretical Comparison Between Integrated and Realized Volatility. Journal of Applied Econometrics 17:479-508.

Merton, R. C. 1973. An Intertemporal Capital Asset Pricing Model. Econometrica 41:867-87.

Merton, R. C. 1980. On Estimating the Expected Return on the Market. Journal of Financial Economics 8:32361.

Mixon, S. 2007. The Implied Volatility Term Structure of Stock Index Options. Journal of Empirical Finance 14:333-54.

Newey, W. K., and K. D. West. 1987. A Simple Positive Semi-Definite, Heteroskedasticity and Autocorrelation Consistent Covariance Matrix. Econometrica 55:703-8. 
Nyberg, P., and A. Wilhelmsson. 2007. Volatility Risk Premium, Risk Aversion and the Cross-Section of Stock Returns. Working Paper, Swedish School of Economics and Business Administration.

Rosenberg, J. V., and R. F. Engle. 2002. Empirical Pricing Kernels. Journal of Financial Economics 64:341-72.

Schwert, G. W. 1990. Stock Volatility and the Crash of '87. Review of Financial Studies 3:77-102.

Scruggs, J. T. 1998. Resolving the Puzzling Intertemporal Relation Between the Market Risks Premium and Conditional Market Variance: A Two-Factor Approach. Journal of Finance 53:575-603.

Stambaugh, R. F. 1986. Bias in Regressions with Lagged Stochastic Regressors. Working Paper, Graduate School of Business, University of Chicago.

Stambaugh, R. F. 1999. Predictive Regressions. Journal of Financial Economics 54:375-421.

Todorov, V. 2007. Variance Risk Premium Dynamics. Working Paper, Northwestern University.

Weil, P. 1989. The Equity Premium Puzzle and the Risk Free Rate Puzzle. Journal of Monetary Economics 24:401-21.

Wu, L. 2005. Variance Dynamics: Joint Evidence from Options and High-Frequency Returns. Working Paper, Baruch College at CUNY.

Zhang, L., P. A. Mykland, and Y. Aït-Sahalia. 2005. A Tale of Two Time Scales: Determining Integrated Volatility with Noisy High-Frequency Data. Journal of the American Statistical Association 100:1394-411.

Ziegler, A. 2007. Why Does Implied Risk Aversion Smile? Review of Financial Studies 20:859-904. 